\title{
REPRESENTAÇÕES DE GÊNERO NA MÍDIA: ANÁLISE DE TRÊS COMERCIAIS DA MARCA HEINEKEN
}

\author{
JERUSA PIRES POZZADA ${ }^{1}$ \\ ROBERTA RODRIGUES SILVEIRA ${ }^{2}$ \\ LEDIANE TEIXEIRA PASSOS ${ }^{3}$
}

Resumo: O presente trabalho visa discutir sobre as representações de gênero na mídia e na publicidade, através de três propagandas da cerveja Heineken. Foi observado que, ao longo do tempo, houve avanços significativos na maneira como a figura da mulher faz-se presente nos comerciais desta marca de cerveja, embora também se perceba que alguns aspectos ainda reproduzem o sexismo, machismo e inferiorização das mulheres na sociedade.

Palavras-chave: Representações de gênero. Publicidade. Estereótipos.

Abstract: The present work aims at discussing the representations of gender in the media and in advertising through three Heineken beer advertisements. It has been observed that, over time, there have been significant advances in the way the figure of women is present in the commercials of this brand of beer, although it is also perceived that some aspects still reproduce sexism, chovinism and inferiorization of women in society.

Key words: Representations of gender. Advertising. Stereotypes.

Resumen: El presente trabajo trata de discutir sobre las representaciones de género en los medios y en la publicidad, a través de tres anuncios de la cerveza Heineken. Se observó que, a lo largo del tiempo, hubo avances significativos en la manera como la figura de la mujer se hace presente en los comerciales de esta marca de cerveza, aunque también se percibe que algunos aspectos todavía reproducen el sexismo, el machismo y la inferiorización de las mujeres en la sociedad.

Palabras clave: Representaciones de género. Publicidad. Estereotipos.

Ao longo da história a mulher vem lutando por seu espaço e pela conquista de seus direitos na sociedade. Apesar de muitos avanços, ainda pode se observar ações que mantém a marca do sexismo, do machismo e da inferiorização pelos quais o público feminino passa. Muitos dos discursos que fomentam estas ideias se fazem presentes na

\footnotetext{
${ }^{1}$ Acadêmica do curso de Psicologia da Universidade Federal do Rio Grande - FURG. Rio Grande, RS, Brasil.

${ }^{2}$ Acadêmica do curso de Psicologia da Universidade Federal do Rio Grande- FURG. Rio Grande, RS, Brasil.

3 Acadêmica do curso de Psicologia da Universidade Federal do Rio Grande - FURG. Rio Grande, RS, Brasil.
}

Rev. Diversidade e Educação, v. 5, n. 1, p. 65-71, jan./jun. 2017. 
publicidade, que é um dos veículos responsáveis pela transmissão de valores e representações presentes no cotidiano da sociedade - tais como o ser homem e o ser mulher - já que suas mensagens não costumam ser neutras, considerando seu objetivo, que é a promoção, aceitação e comercialização de produtos.

Em um período de tempo de segundos as empresas buscam a identificação do consumidor com o produto, portanto, a publicidade "é o espelho da sociedade em que ela está. Ela não cria hábitos, ela retrata hábitos. Não é papel dela mudar tendências, condutas ou costumes, mas sim reproduzi-los" (SILVA et al., 2016). Também, como reforça Oliveira e Cancela (2012, p. 40), “um dos objetivos do meio publicitário é retratar o modo de viver e pensar da sociedade, mas, ao mesmo tempo, criar modos de viver e pensar para imbuir ao meio social".

Tendo em vista a busca pela identificação do consumidor, marcas de cerveja, destinadas majoritariamente ao público masculino, costumam produzir comerciais que trazem a imagem da mulher como objeto de consumo, tanto quanto a cerveja. A Heineken é uma marca mundialmente conhecida por produzir propagandas vistas como criativas e que se aproximam do cotidiano do público, mas também costuma utilizar estas representações femininas em seus comerciais. Assim, optou-se por analisar três propagandas desta marca de cerveja para este artigo, tendo como propósito discutir as representações de gênero presentes, nas quais se observa uma mudança de padrão.

Uma delas, lançada em 2009 foi intitulada "Walk in the Fridge" (Figura 1 e 2). O comercial retrata uma festa na casa de um casal. A dona da casa está mostrando os cômodos a três amigas e ela finaliza o tour apresentando um closet cheio de sapatos e roupas levando as amigas ao delírio e a satisfação da anfitriã. Neste momento, começase a ouvir gritos de homens e a imagem passa ao dono da casa mostrando um closet com a mesma estrutura que o mostrado pela mulher, mas cheio de freezers e prateleiras ocupadas por garrafas da cerveja, o que também leva ao delírio três amigos.

Rev. Diversidade e Educação, v. 5, n. 1, p. 65-71, jan./jun. 2017. 


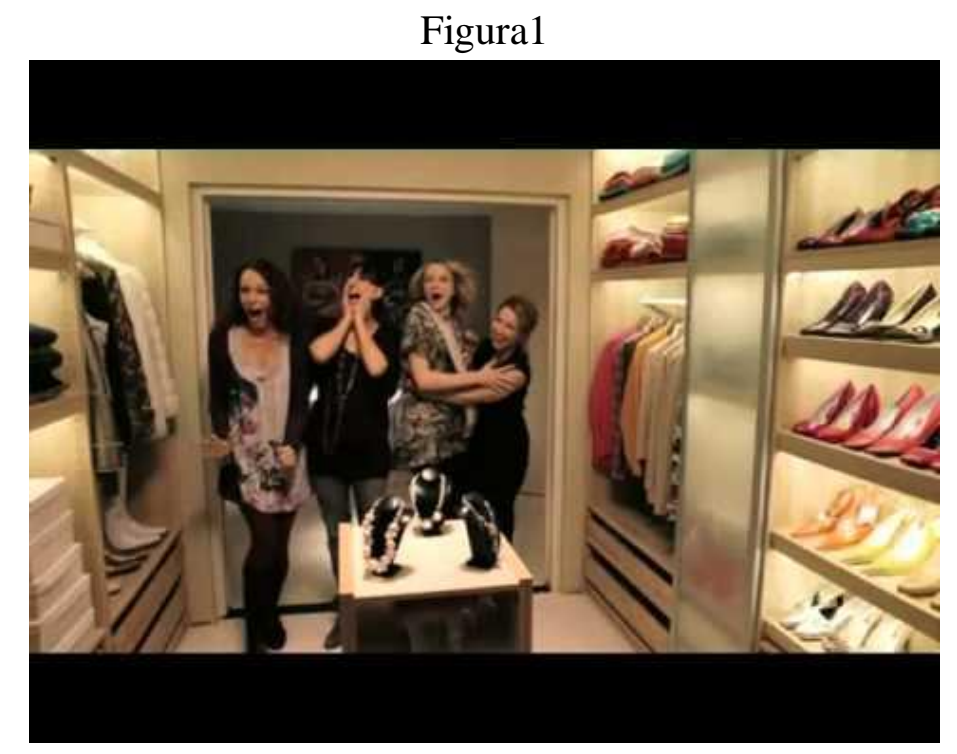

Fonte: https://i.ytimg.com/vi/9eydFi6pz-s/hqdefault.jpg

Figura 2

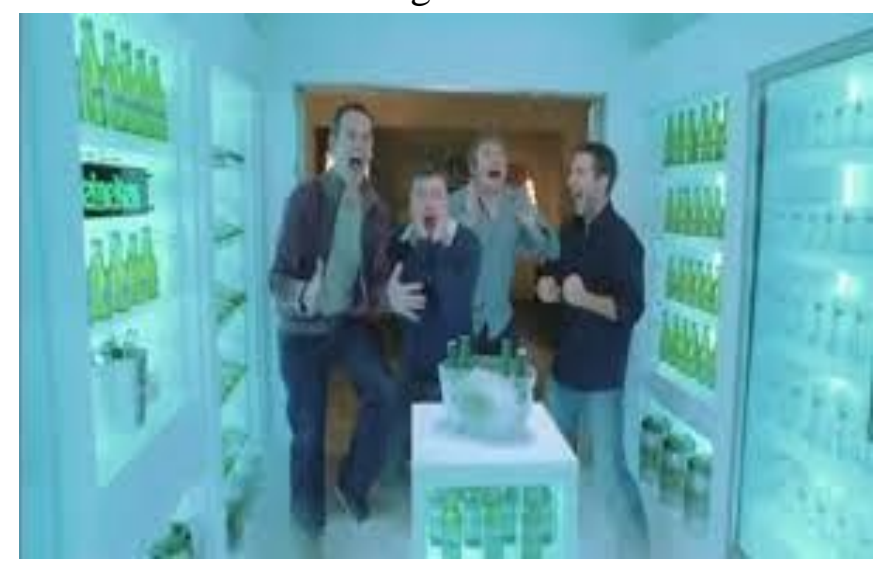

Fonte: https://i.ytimg.com/vi/ya96WSJnJG4/maxresdefault.jpg

Esta propaganda gerou muita empatia tanto do público feminino quanto masculino e foi eleita por diversos sites que discursam sobre publicidade como uma das mais engraçadas da categoria. Mas, apesar disso, deixam claras as representações de gênero muito presentes em campanhas publicitárias, como as de que "mulheres gostam de roupas/sapatos, homens de cerveja", o que, por muitos anos, foi sendo utilizado pela própria Heineken em suas campanhas.

Segundo Siqueira, Modesto e Souza (2015), “as representações nos comerciais refletem padrões estabelecidos socialmente, sendo convencional a construção de estereótipos dos modelos masculinos e femininos". Vê-se constantemente estes Rev. Diversidade e Educação, v. 5, n. 1, p. 65-71, jan./jun. 2017. 
marcadores construídos e reforçados através da mídia: a mulher com imagem de dona de casa responsável pelos afazeres domésticos, fútil e com compulsão pelo consumo, ou erotizada; homens fortes e viris, independentes e de negócios, amantes de cerveja, futebol e mulher. Muitos desses estereótipos passam pelo imaginário popular e não chegam a ser questionados, pois são reforçados e apoiados pelo senso comum. "O que o estereótipo faz é criar a imagem (...) aceita e partilhada socialmente por um grupo de pessoas que se identificam com tal imagem" (SIQUEIRA; MODESTO; SOUZA, 2015). Mas isto, apesar de há muito tempo vir sendo constantemente reforçado, tem sido modificado através de movimentos e manifestações sociais que buscam a quebra de rótulos e a construção de novos conceitos de feminino e masculino que representem mais fielmente a população.

É possível se traçar uma linha do tempo entre as propagandas da Heineken de 2009, 2014 e 2016 e pensar as modificações nas formas de representar a figura da mulher. Em 2014, a publicidade da Heineken segue na mesma direção da de 2009 (já apresentada). A propaganda desse ano, chamada "Heineken Shoe Sale" (Figura 3), consistiu na promoção de uma liquidação de sapatos para as mulheres nas lojas e no site da marca Shoestock, exatamente no dia e hora da Final da UEFA Champions League, campeonato de futebol europeu que a Heineken patrocina desde 2005.

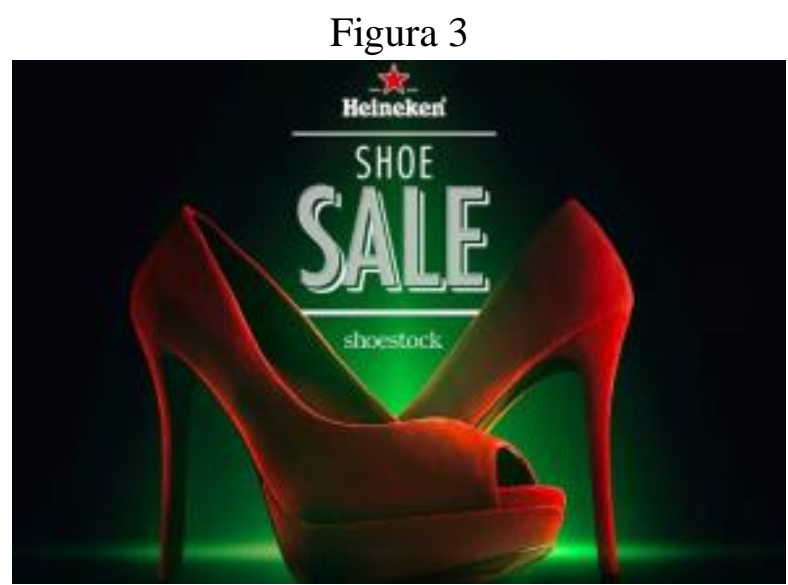

Fonte: http://www.adweek.com/wp-content/uploads/files/blogs/heineken-shoe-sale-hed2014.png

No comercial são utilizadas frases como "tudo para ela pensar somente em sapatos em vez de onde você está" e "você, feliz com seus amigos; sua mulher, feliz com você". Percebe-se, novamente, a representação dicotômica de que mulheres se interessam por calçados, compras e estética, e os homens por cerveja e futebol,

Rev. Diversidade e Educação, v. 5, n. 1, p. 65-71, jan./jun. 2017. 
desconsiderando o fato de que as mulheres podem gostar de futebol e os homens de fazer compras.

Em 2016, com o aumento das discussões de gênero em espaços como a internet e a televisão e uma maior possibilidade de reflexão sobre o assunto, a Heineken valeuse das temáticas que já eram recorrentes em suas propagandas (gênero e futebol) e lançou a propaganda "The cliché" (Figura 4 e 5). Nela, uma semana antes da final da UEFA Champions League, três casais heterossexuais vão a um restaurante e o garçom entrega o cardápio para os homens. No cardápio há um cartão para eles presentearem as namoradas com um fim de semana em um spa, e ficarem livres para assistir à final do campeonato em uma festa da Heineken. Na referida festa, aparece uma tela com a mensagem: "Curtam a final assim como suas mulheres estão curtindo o spa" e em seguida é mostrada a imagem das mulheres com roupão de banho, comentando que estão curtindo muito o lugar. Porém, neste momento, o cenário cai e as mulheres gritam que "está maravilhoso em Milão", no estádio que ocorrerá o jogo. Aparecem as mulheres no estádio vibrando pelo jogo e os homens perplexos com a surpresa.

Figura 4

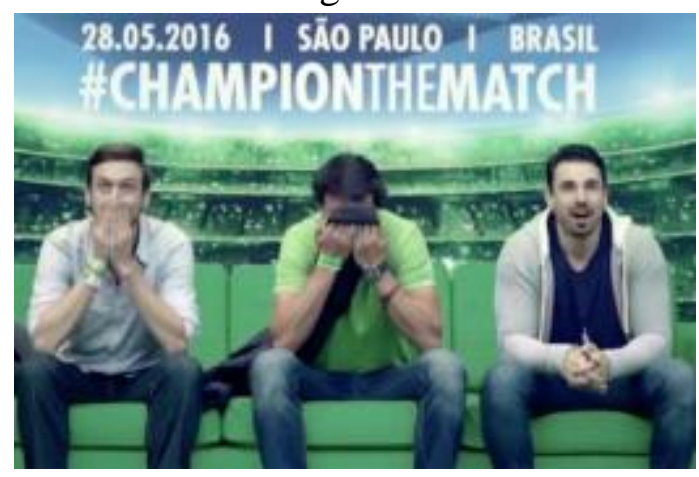

Fonte: http://assets.creativityonline.com/images/work/full/h/e/i/Heineken_TheCliche16.jpg

Figura 5

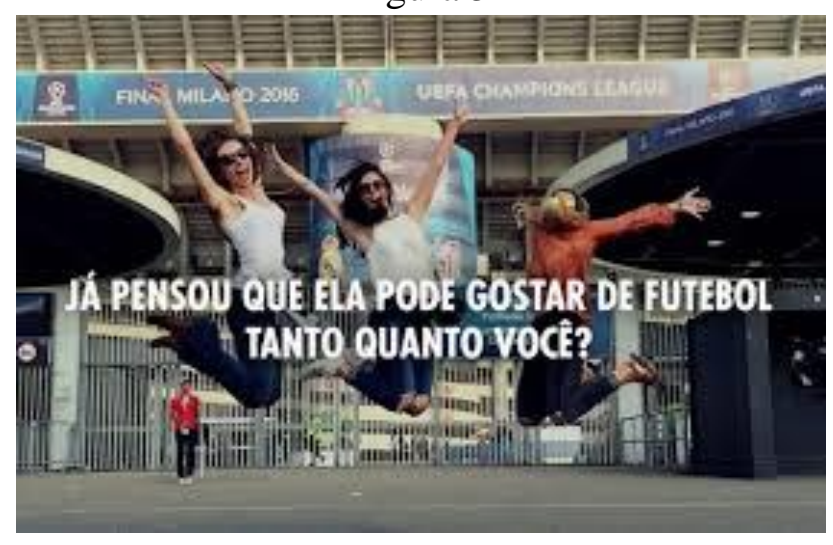

Rev. Diversidade e Educação, v. 5, n. 1, p. 65-71, jan./jun. 2017. 
Fonte: https://www.agambiarra.com/wp-content/uploads/2016/06/heineken-the-cliche1-agambiarra.jpg

Comparada com as anteriores, percebe-se a modificação do formato e conteúdo da propaganda, deixando de focar na associação das mulheres com roupas e sapatos e trazendo uma nova perspectiva. Isso, por si só, é uma desconstrução e um avanço em um comercial de cerveja, que costuma sempre abordar a mulher como um objeto. Porém, é importante ser pontuado que ainda persiste a ideia da beleza e futilidade da mulher, por conta da parte inicial, em que seus namorados creem que elas prefeririam disfrutar de um spa para relaxar e ficarem mais belas e que desta forma eles estariam livres para assistirem o jogo.

Diante do exposto, uma vez que a publicidade tem o papel de reproduzir hábitos da sociedade, entende-se que poderia buscar acompanhar as mudanças tendentes nos movimentos sociais relacionados às questões de gênero. Tendo em vista que os sujeitos se constroem sócio-histórico-culturalmente, essas representações de feminilidades e masculinidades foram construídas ao longo da história e por esse mesmo motivo podem ser desfeitas. Ao se proporcionar espaços educativos de reflexão, que problematizem questões de gênero que estão naturalizadas, é possível que essas desconstruções aconteçam. Além disso, é possível que essas discussões atinjam os diferentes espaços, problematizando e rompendo com essas ideias em variados meios, entre eles a televisão e a publicidade, entendendo que estes são meios acessíveis e formadores de opinião para muitas pessoas. Assim, essas representações de gênero instituídas na sociedade, como a de que, exclusivamente, mulheres gostam de roupas e sapatos e homens de cerveja, podem ser repensadas e modificadas.

\section{Referências}

OLIVEIRA, Robson C.; CANCELA, Cristina D. Hierarquia em evidência: um retrato da dominação hegemônica de masculinidade na propaganda de cerveja. Revista NUFEN, São Paulo, v. 4, n. 2, p. 37-48, jul./dez. 2012.

SILVA, Camila B.; KETTERMANN, Beatriz J.; CERETA, Sabrina; NIELSSON, Joice G. Violência de gênero e mídia digital: uma complexa e conturbada relação. In: SALÃO

Rev. Diversidade e Educação, v. 5, n. 1, p. 65-71, jan./jun. 2017. 
DO CONHECIMENTO UNIJUÍ, XXIV Seminário de Iniciação Científica, 2016.

Anais... Ijuí: UNIJUÍ, 2016. Não paginado.

SIQUEIRA, Wender R.; MODESTO, Munique C.; SOUZA, Carla M. A Representação do Gênero Feminino nas Propagandas da Cerveja Antarctica: Bar da Boa. In: CONGRESSO INTERNACIONAL EM COMUNICAÇÃO E CONSUMO, GT 2:

Comunicação, Consumo e Identidade do $5^{\circ}$ Encontro de GT's de Pós-Graduação, 2015. Anais... São Paulo: ESPM, 2015. Não paginado.

Recebido em: 05/06/2017 Aprovado em: 23/08/2017

Rev. Diversidade e Educação, v. 5, n. 1, p. 65-71, jan./jun. 2017. 